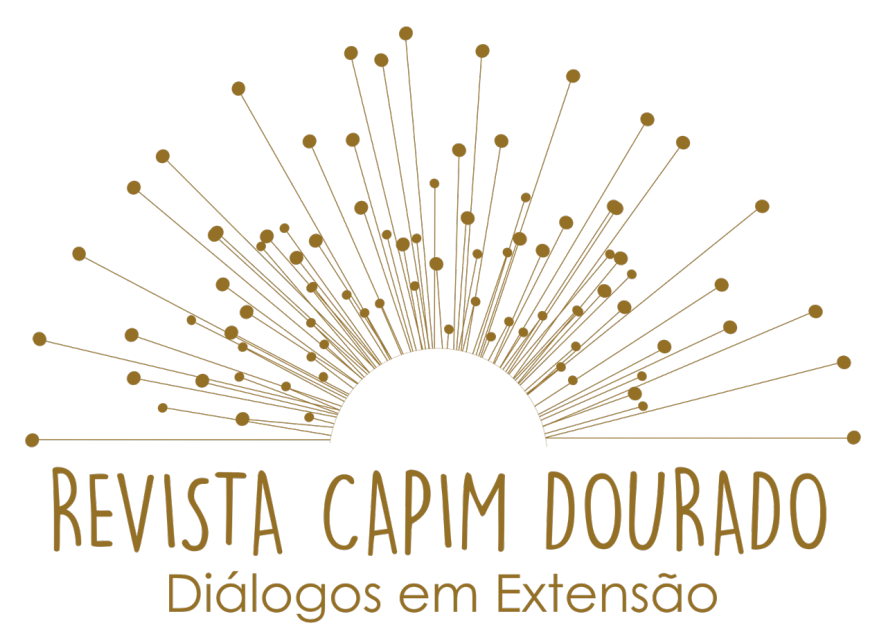

ISSN n² 2595-7341

Vol. 3, n. 1, Janeiro-Abril, 2020

DOI: http://dx.doi.org/10.20873/uft.2595-7341.2020v3n1p76

\title{
ESCORPIÕES: UM ESTUDO DE CASO COM ALUNOS DO ENSINO FUNDAMENTAL EM ESCOLAS DOS MUNICÍPIOS DE PORTO NACIONAL-TO
}

SCORPIONS: A CASE STUDY WITH STUDENTS OF FUNDAMENTAL EDUCATION IN SCHOOLS IN THE MUNICIPALITIES OF PORTO NACIONAL-TO

\section{ESCORPIONES: ESTUDIO DE CASO CON ESTUDIANTES DE EDUCACIÓN FUNDAMENTAL EN ESCUELAS DE LOS MUNICIPIOS DE PORTO NACIONAL-TO}

\section{Derval Nt Gomes Ribeiro ${ }^{1}$ \\ Yara Gomes Corrêa ${ }^{2}$ \\ Carla Simone Seibert ${ }^{3}$}

\section{RESUMO}

A educação ambiental pode ajudar na sensibilização da sociedade em relação aos escorpiões, desmistificando a visão antropocêntrica no qual o indivíduo se põe acima dos animais não humanos e da natureza, bem como a promover uma interação socioambiental mais justa entre ambos e o ambiente. Conhecer o animal não humano em seu habitat e respeita-lo como tal, pode ajudar na preservação das espécies de escorpião, bem como prevenir acidentes. Para

\footnotetext{
${ }^{1}$ Biólogo, Mestrando do Programa de Pós-Graduação em Ciências do Ambiente, Universidade Federal do Tocantins (UFT), Campus de Palmas, TO, derval@uft.edu.br.

2 Bióloga, Mestre em Ciências do Ambiente, Doutoranda do Programa de Pós-graduação em Ciências do Ambiente, Universidade Federal do Tocantins (UFT), Campus de Palmas; yaragc@mail.uft.edu.br

${ }^{3}$ Prof. $^{a}$ Dr. ${ }^{a}$ Curso de Ciências Biológicas/Porto Nacional e Programa de Pós-Graduação do PPGCiamb/Palmas/UFT. seibertcs@uft.edu.br
} 


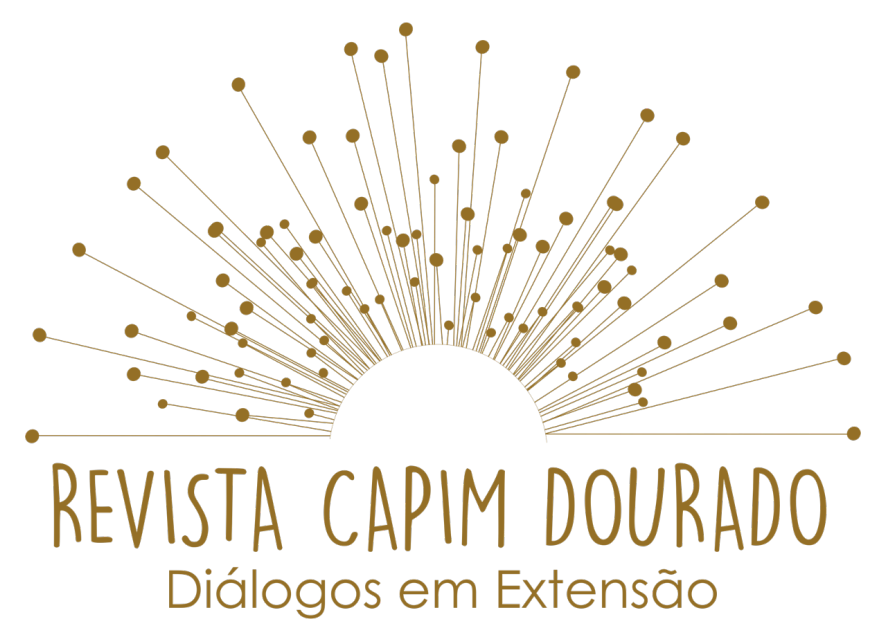

ISSN n² 2595-7341

Vol. 3, n. 1, Janeiro-Abril, 2020

DOI: http://dx.doi.org/10.20873/uft.2595-7341.2020v3n1p76

melhorar a relação entre ser humano e animais não humanos, foi desenvolvido um trabalho socioambiental com crianças de 11 a 12 anos, por meio de realização de oficinas com apresentação de materiais didáticos sobre os escorpiões. Foi elaborado um questionário contendo oito questões de fácil interpretação e resposta. As perguntas demonstraram valores significativos de dependência do pós teste em relação a oficina, sendo possível dizer que os sujeitos participantes possuem uma visão convencional acerca dos escorpiões, que pode ser modificada com uma interversão didático-metodológica intencional.

PALAVRAS-CHAVE: Tityus sp. Sensibilização. Crianças. Interação Socioambiental.

\section{ABSTRACT}

Environmental education can help raise society's awareness of scorpions, demystifying the anthropocentric view in which the individual stands above nonhuman animals and nature, as well as promoting a more just socio-environmental interaction between both and the environment. Knowing the non-human animal in its habitat and respecting it as such can help to preserve scorpion species, as well as prevent accidents. In order to improve the relationship between human beings and non-human animals, socioenvironmental work was carried out with children aged 11 to 12 years, through workshops with the presentation of teaching materials on scorpions. A questionnaire was prepared containing eight questions that are easy to interpret and answer. The questions showed significant values of post-test dependence in relation to the workshop, and it is possible to say that the participating subjects have a conventional view about scorpions, which can be modified with an intentional didactic-methodological intervention.

KEYWORDS: Tityus sp. Awareness. Children. Social and Environmental Interaction. 


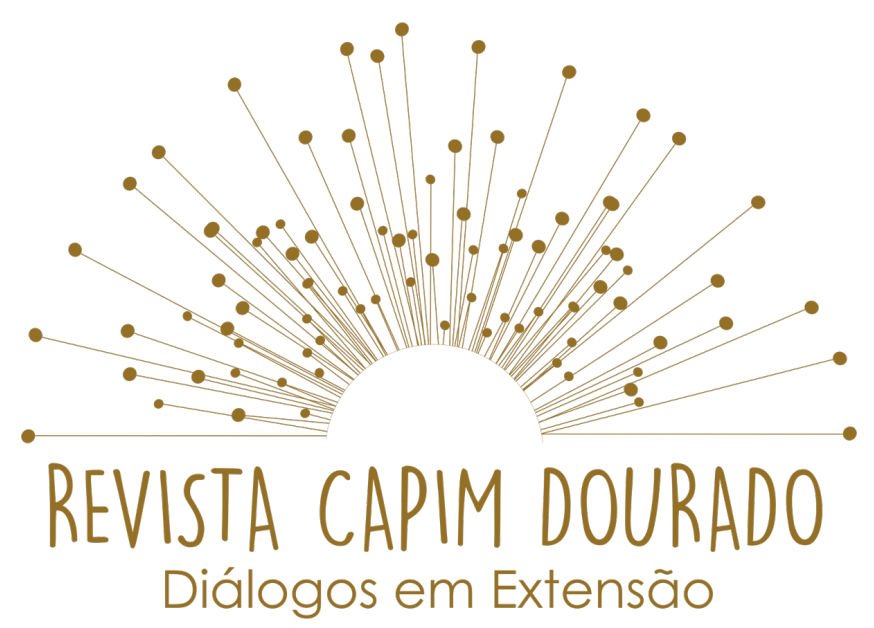

ISSN n² 2595-7341

Vol. 3, n. 1, Janeiro-Abril, 2020

DOI: http://dx.doi.org/10.20873/uft.2595-7341.2020v3n1p76

\section{RESUMEN}

La educación ambiental puede ayudar a aumentar la conciencia de la sociedad sobre los escorpiones, desmitificando la visión antropocéntrica en la que el individuo está por encima de los animales no humanos y la naturaleza, además de promover una interacción socioambiental más justa entre ambos y el medio ambiente. Conocer al animal no humano en su hábitat y respetarlo como tal puede ayudar a preservar las especies de escorpión, así como a prevenir accidentes. Con el fin de mejorar la relación entre los seres humanos y los animales no humanos, se realizó un trabajo socioambiental con niños de 11 a 12 años, a través de talleres con la presentación de materiales didácticos sobre escorpiones. Se elaboró un cuestionario que contiene ocho preguntas de fácil interpretación y respuesta. Las preguntas mostraron valores significativos de dependencia post-test en relación al taller, y se puede decir que los sujetos participantes tienen una visión convencional sobre los escorpiones, que puede modificarse con una intervención didáctico-metodológica intencionada.

PALABRAS CLAVE: Tityus sp. Conciencia. Niños. Interacción social y ambiental.

Recebido em: 01.10.2019. Aceito em: 09.10.2019. Publicado em: 01.01.2020. 


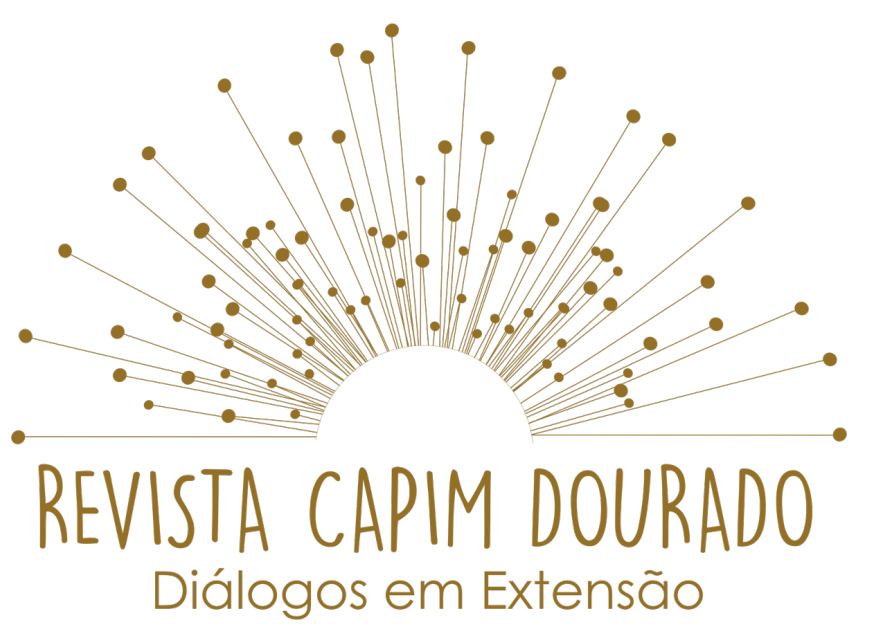

ISSN n² 2595-7341

Vol. 3, n. 1, Janeiro-Abril, 2020

DOI: http://dx.doi.org/10.20873/uft.2595-7341.2020v3n1p76

\section{INTRODUÇÃO}

Os escorpiões pertencem ao filo Arthropoda, subclasse Arachnida e não são insetos, como pensam erroneamente algumas pessoas (MARTINS et al., 2008). Assim, como todos os aracnídeos, o corpo dos escorpiões é dividido em prossoma (cefalotórax) e opistossoma (abdômen). Contudo, o que difere esta ordem dos demais aracnídeos é a divisão do opistossoma em duas partes, ou seja: mesossoma (tronco) e metassoma (cauda).

Estes animais podem ser encontrados desde pedras cobertas por neve a desertos áridos, ou até mesmo em florestas tropicais úmidas (Gopalakrishnakone et al., 2015). Os escorpiões são unicamente carnívoros e sua dieta é composta por aranhas, grilos e baratas. As preferências variam segundo a espécie, seu tamanho, e a quantidade de alimento disponível, além do tipo e tamanho da presa (Martins et al., 2008).

O escorpião utiliza o seu veneno para capturar e imobilizar suas presas, no entanto, 25 espécies são potencialmente nocivas aos seres humanos e apenas quatro são encontradas no Brasil (GOPALAKRISHNAKONE et al., 2015). O índice de mortalidade por acidentes com escorpião é relativamente baixo, sendo idosos e crianças os mais vulneráveis (ARAÚJO et al., 2003).

São poucos os estudos epidemiológicos para o estado do Tocantins. $O$ estudo de Parise (2016) detalha o quadro de incidência dos acidentes para o município de Palmas, tendo sido notificados 1.102 acidentes por escorpiões, em 14 anos. Entretanto, não há estudos com enfoque etnoaracnológico no ensino de Biologia, envolvendo escorpiões e os saberes populares de crianças em idade 


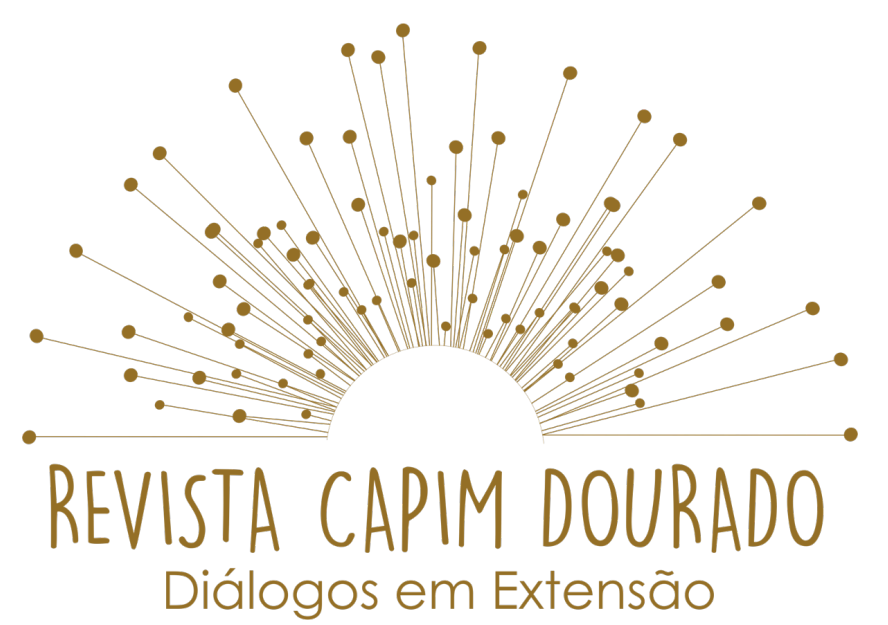

ISSN n² 2595-7341

Vol. 3, n. 1, Janeiro-Abril, 2020

DOI: http://dx.doi.org/10.20873/uft.2595-7341.2020v3n1p76

escolar no ensino fundamental, o que torna este trabalho relevante e pioneiro, uma vez que este é o grupo de risco para óbitos nos acidentes com escorpião. Diante do exposto, objetivamos registrar a concepção de alunos do ensino fundamental dos municípios de Porto Nacional - TO, sobre os escorpiões.

\section{METODOLOGIA}

O estudo foi realizado em três escolas situadas na área urbana do município de Porto Nacional - TO: Escola Municipal Padre Luso Matos, Escola Municipal Dr. Euvaldo Tomaz de Souza e Escola Municipal Fanny Macedo Pereira. Para esse estudo o público alvo compreendeu 34 estudantes do $5^{\circ}$ ano do ensino fundamental, de cada escola.

Foi efetuado o contato anterior com os diretores das escolas participantes para proceder a autorização e apresentar formalmente os objetivos do grupo de pesquisadores do Projeto de Extensão intitulado "O storytelling para a sensibilização do público infantil sobre animais peçonhentos" (CORRÊA; SEIBERT, 2019).

A primeira atividade na escola foi a aplicação de um questionário prévio, contendo 10 perguntas fechadas, com alternativas curtas, para conhecer a compreensão precedente dos sujeitos sobre os escorpiões. Na segunda visita à escola, foi realizada uma oficina sobre os animais peçonhentos e os escorpiões. A duração dessa atividade foi de duas horas-aula, período em que houve um momento para a utilização da técnica de diálogo em círculo, com exposição de material didático e biológico. A seguir, os alunos foram convidados a preparar 


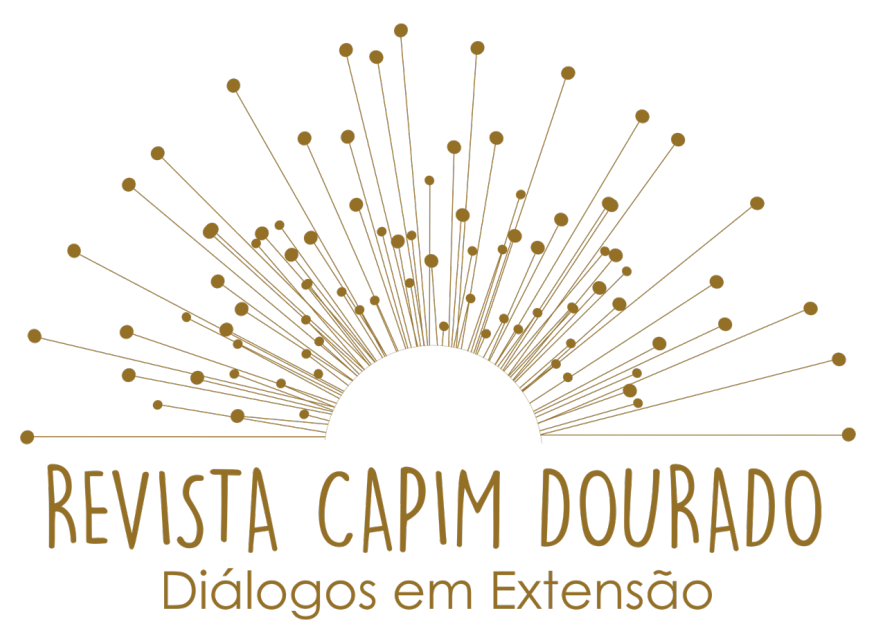

ISSN n² 2595-7341

Vol. 3, n. 1, Janeiro-Abril, 2020

DOI: http://dx.doi.org/10.20873/uft.2595-7341.2020v3n1p76

um teatro de fantoches de palitos, contendo personagens de escorpiões, seus predadores naturais e seres humanos, em cenário pertinente ao encontro entre o animal e o ser humano, previamente confeccionados pelos organizadores. Para avaliar e comparar o aprendizado dos sujeitos participantes aplicou-se o mesmo questionário ao final da oficina.

\section{FUNDAMENTAÇÃO TEÓRICA}

A taxonomia é a ciência da identificação. Talvez, a mais velha de todas as ciências, pois nasceu com o ser humano, e, com toda certeza, a mais necessária, sendo a habilidade de classificar e identificar os animais e plantas que fizeram com que o homem soubesse por exemplo distinguir entre o que era um animal peçonhento e um animal venenoso (BICUDA, 2004). Sendo assim, as primeiras questões do presente trabalho tinham como objetivo avaliar o aprendizado do estudante em relação ao grupo taxonômico dos escorpiões. Portanto, estes responderam se o grupo é da classe dos aracnídeos, no pré-teste boa parte dos estudantes desconhecia este fato, já no pós-teste o número de estudantes que marcaram que os escorpiões são aracnídeos foi muito maior, o que está relacionado ao aprendizado do estudante após a oficina.

Atividades práticas, como as desenvolvidas na oficina, são excelentes métodos para aprender taxonomia, onde o estudante tem um contato diretamente com o animal não humano. Além disso, mesmo os estudantes que possuíam um conhecimento prévio sobre os escorpiões mudaram seus conceitos relacionados a este artrópode, o que sugere que o conhecimento adquirido em sala de aula, é assimilado e acomodado (PIAJET, 1997). É necessário unir a teoria 


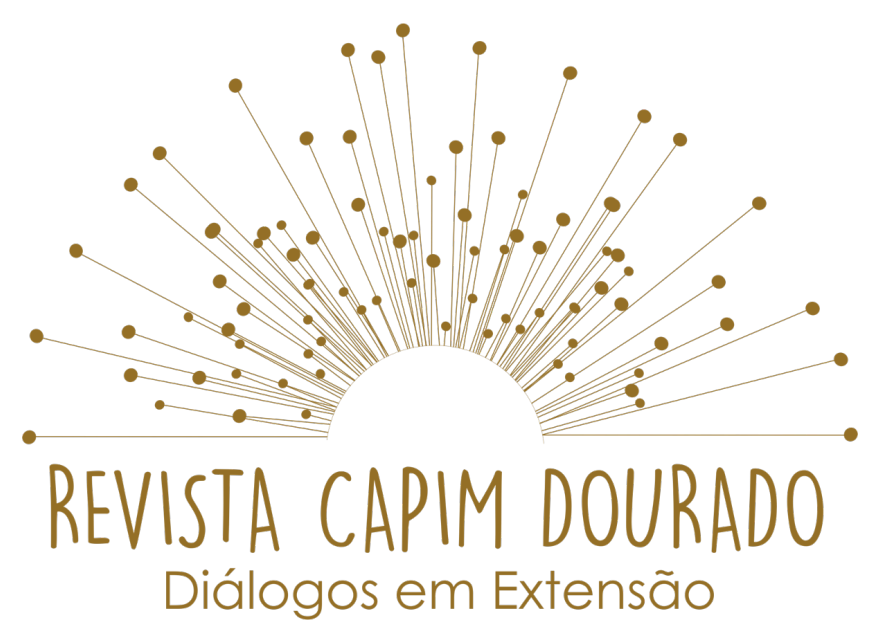

ISSN n² 2595-7341

Vol. 3, n. 1, Janeiro-Abril, 2020

DOI: http://dx.doi.org/10.20873/uft.2595-7341.2020v3n1p76

à prática para que o estudante construa, com a colaboração dos professores e dos conteúdos ministrados, sua própria visão de mundo, só que agora concreta, a partir de sua experiencia vivida na oficina.

É garantida a relação entre a teoria e a prática através do sincronismo e harmonia, da autonomia e dependência de uma em relação a outra. No entanto, é necessário compreender que esta afinidade faz parte do processo pelo qual se constrói o conhecimento (VEIGA, 2012). Desde as idades iniciais se deve começar a estimular o equilíbrio entre o homem e o ambiente entre o animal humano e o não humano (TEXEIRA et. al., 2017).

Sobretudo, os estudantes demostraram uma aversão aos escorpiões, algo evidenciado pelas respostas da maioria dos estudantes que relataram que estes pequenos artrópodes não são importantes para o meio ambiente, esta aversão por parte dos estudantes pode estar relacionada aos acidentes sofridos por parte dos parentes e amigos próximos, algo que corrobora com Martins et. al., (2008) e é evidenciado quando o número de aversões a escorpiões é diminuído de acordo com a região de residência dos estudantes.

\section{RESULTADOS FINAIS}

Os estudantes que participaram das atividades apresentaram uma faixa etária entre 10 e 12 anos de idade, sendo que $68 \%$ eram meninas e $32 \%$ eram meninos. Quando perguntados se sabiam o que era um aracnídeo, no questionário prévio $38 \%$ disseram que não sabiam, porém após a oficina esse índice caiu para 9\%. 


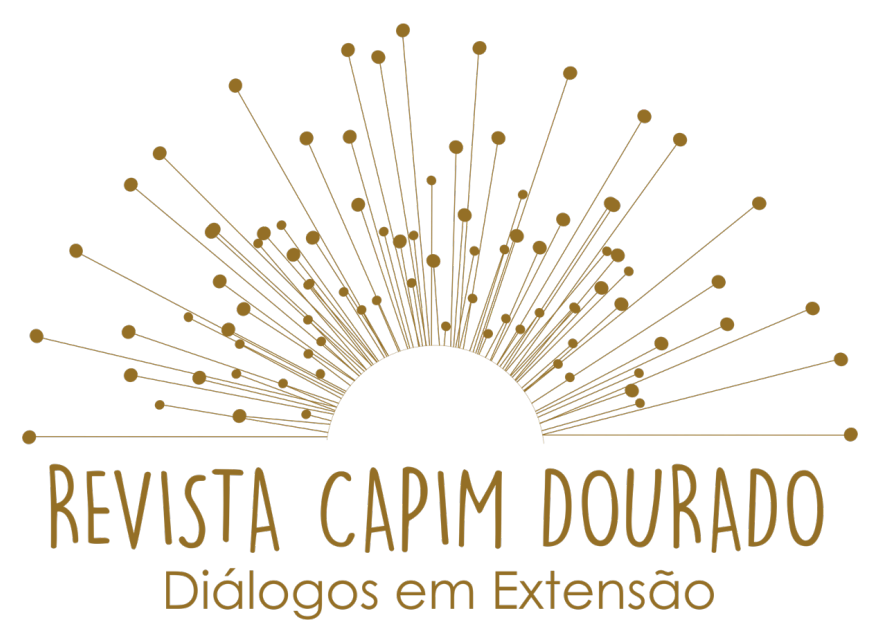

ISSN n² 2595-7341

Vol. 3, n. 1, Janeiro-Abril, 2020

DOI: http://dx.doi.org/10.20873/uft.2595-7341.2020v3n1p76

Quando indagados se já haviam visto um escorpião na região onde moram ou estudam, 50\% dos sujeitos afirmaram que sim, e no questionário posterior à oficina esse índice aumentou para $68 \%$, o que demonstra que anteriormente os jovens não sabiam o que de fato era um escorpião.

Ao abordarmos a importância dos escorpiões para o meio ambiente, no questionário prévio, $71 \%$ dos sujeitos marcaram que o animal não é importante para o meio, porém após a oficina esse índice caiu para $47 \%$.

Os resultados alcançados no questionário pós-oficina, quando comparado às histórias contadas pelos estudantes, durantes o teatro de fantoches com palitos, são convergentes. Isto vem ao encontro de estudos similares que também usaram alguma técnica de contação de histórias. O narrador reapresenta um conhecimento já existente, reconfigurando o modo como é contado, acrescentando aspectos subjetivos que tornem o fato narrado uma linguagem contextualizada, procurando aproximar os interlocutores (FONTANA, 2009).

\section{CONSIDERAÇÕES FINAIS}

É possível concluir que os sujeitos participantes possuem uma visão convencional acerca dos escorpiões, que pode ser modificada com uma interversão didático-metodológica intencional. Há intolerância humana em relação à presença do escorpião, quer em suas residências ou em outros ambientes urbanos. Levar a informação por meio de sensibilizações pode modificar essa relação, fazendo-os entender a importância desses animais para o ambiente. 


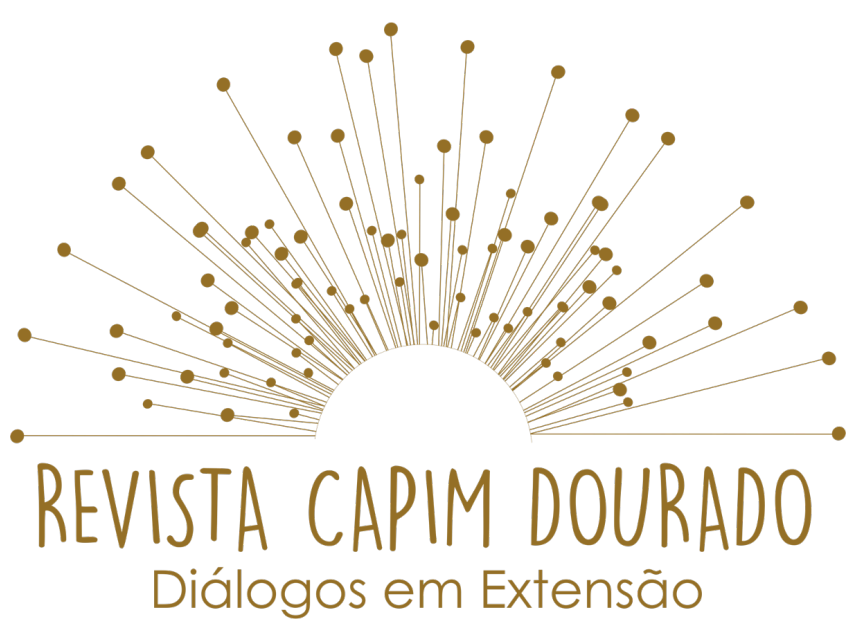

ISSN n² 2595-7341

Vol. 3, n. 1, Janeiro-Abril, 2020

DOI: http://dx.doi.org/10.20873/uft.2595-7341.2020v3n1p76

\section{REFERÊNCIAS}

ARAÚJO, F. A.; SANTALÚCIA, M.; CABRAL, R. F. Epidemiologia dos acidentes por animais peçonhentos. In: Animais peçonhentos no brasil: biologia, clínica e terapêutica dos acidentes (CARDODO et al.), 2003.

BICUDA, C.E. de M. Taxonomia. Editorial. v. 4, n. 1. Biota Neotrop. Campinas DOI: (http://dx.doi.org/10.1590/S1676-06032004000100001). 2004.

CORRÊA, Y. G.; SEIBERT, C. S. Uso do Storytelling na educação ambiental para sensibilizar crianças sobre as arraias de água doce. Ambiente \& Educação-Revista de Educação Ambiental, v. 24, n. 1, p. 3-31, 2019.

FONTANA, A. Manuale di Storytelling: reccontare com efficacia prodotti, marchi e identità d'impresa. Bologna: ETAS, 2009, 240 p.

GOPALAKRISHNAKONE P.; POSSANI, L. D.; SCHWARTZ, E. F.; DE LAVEGA, R. C. R. Scorpion Venoms. 2015.

MARTINS, M. R.; RAFAINE, D.; NEVES, M. F.; SACCO, S. R. Escorpiões: Biologia e acidentes. Revista Científica Eletrônica de Medicina Veterinária, ano VI, n. 10, 2008.

PIAGET, J. As Formas Elementares da Dialética. (Luiz, F.M. Trad.) São Paulo: Casa do Psicólogo, 1997. (Original publicado em 1980).

TEIXEIRA, C. DE S. B.; MELLO, L.G.; CORREIA, K.N.C.; FREITAS, R. de C.; DA SILVA, T. LELIS B.; SOARES, M. de A. Práticas de Educação Ambiental na prevenção de acidentes com escorpiões na zona oeste do Rio de Janeiro. $6^{\circ}$ Simpósio de Gestão Ambiental e Biodiversidade (20 a 23 de junho 2017) ISSN 2525-4928 http://itr.ufrrj.br/sigabi/anais, 2017.

VEIGA, I.P.A. Nos laboratórios e oficinas escolares: a demonstração da didática. In: VEIGA, I. P. A.. (Org.). Técnicas de Ensino: por que não? 21ª ed.Campinas:

Papirus, p. 131-149. 2012. 